\title{
A BROKEN APPOINTMENT
}

\section{You did not come,}

And marching Time drew on, and wore me numb. Yet less for loss of your dear presence there Than that I thus found lacking in your make That high compassion which can overbear Reluctance for pure lovingkindness' sake Grieved I, when, as the hope-hour stroked its sum, You did not come.

You love not me, And love alone can lend you loyalty;

- I know and knew it. But, unto the store Of human deeds divine in all but name, Was it not worth a little hour or more To add yet this: Once you, a woman, came To soothe a time-torn man; even though it be You love not me?

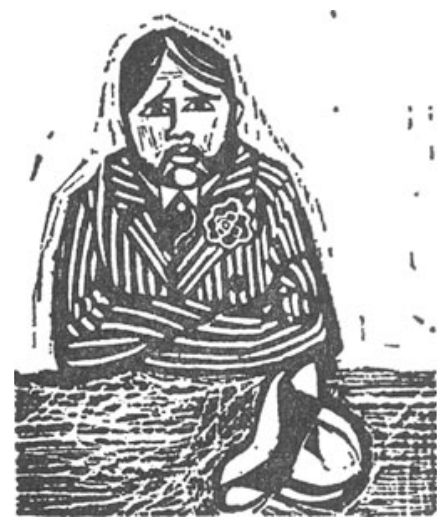

